\title{
Evaluation of Seizures in Patients with Chronic Subdural Hema- toma Treated by Burr-Hole Surgery and Risk Factors for Seizures
}

\author{
Tetsuhisa Yamada ${ }^{*}$ and Yoshihiro Natori ${ }^{2}$ \\ ${ }^{1}$ Department of Emergency Medicine, lizuka Hospital, Japan \\ ${ }^{2}$ Department of Neurosurgery, lizuka Hospital, Japan
}

*Corresponding author: Tetsuhisa Yamada, Department of Emergency Medicine, lizuka Hospital, 3-83 Yoshiomachi, lizuka-city, Fukuoka 820-8505, Japan, Tel: +0948-22-3800, Fax: +0948-29-8747, E-mail: tyamadah4@aih-net.com

\begin{abstract}
Chronic subdural hematoma is one of the most commonly encountered diseases in neurosurgery. The treatment method is well established, but seizures develop as a complication in $2.3 \%$ to $20.4 \%$ of patients. We studied patients with seizures to clarify the status of patients at the onset of seizures and define risk factors for seizures. From January 2000 through December 2014, we studied 1,077 patients with chronic subdural hematomas (1,257 hematomas) who underwent burr-hole surgery in our department. To identify risk factors for seizures, we retrospectively compared the clinical characteristics of patients with seizures with those of patients without seizures.

Seizures associated with chronic subdural hematoma developed in 21 patients (1.95\%) with 22 hematomas (1.75\%). Many patients initially had partial seizures before operation. After hematoma removal, the seizures were relatively well controlled. Risk factors for seizures were disturbed consciousness, hemiplegia, and organized hematoma at presentation. Disturbed consciousness and hemiplegia at presentation were attributed to seizures. Because it was difficult to diagnose organized hematoma solely on the basis of preoperative imaging studies, preoperatively predicting the risk of seizures is considered challenging.
\end{abstract}

\section{Keywords}

Chronic subdural hematoma, Seizure, Burr-hole surgery

\section{Introduction}

Chronic subdural hematoma (CSDH) is one of the most commonly encountered diseases in neurosurgical practices. The diagnosis and treatment of CSDH have been well established. The standard treatment is burr-hole surgery performed with the patient under local anesthesia. Symptoms improve, and the prognosis is good [1]. However, sei- zures have been reported to develop as a complication in $2.3 \%$ to $20.4 \%$ of patients [2-9]. We studied patients with $\mathrm{CSDH}$ in whom seizures developed as a complication to investigate the status of patients at the onset of seizures and clarify risk factors for seizures.

\section{Methods}

A total of 1,085 patients with CSDH (1,257 hematomas) were admitted to the Department of Neurosurgery of our hospital and underwent surgery from January 2000 through December 2014. Craniotomy was performed in 3 patients (4 hematomas), reservoir placement in 5 patients ( 6 hematomas), and burr-hole surgery in 1,077 patients (1,257 hematomas). Burr-hole surgery was initially performed in 968 patients (1,135 hematomas) and was repeated because of recurrence in 109 patients (122 hematomas). We studied the 1,077 patients (1,257 hematomas) who underwent burr-hole surgery. Burr-hole surgery involved the following steps, performed with the patient under local anesthesia: burr-hole opening, irrigation, and hematoma removal. A drainage tube was placed in the hematoma space and was removed on the day after surgery, in principle; however, drainage could be continued at the discretion of the operator if computed tomography (CT) of the head revealed residual hematoma on postoperative day 1.

We studied 1,077 patients with $\mathrm{CSDH}(1,257$ hematomas) who underwent burr-hole surgery under local anesthesia. The observation period was from the date of the diagnosis of CSDH or the onset of symptoms of CSDH to 1 month after operation. Seizures developed as a complica-

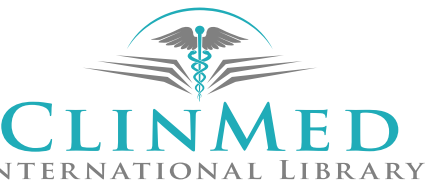

INTERNATIONAL LIBRARY

Citation: Yamada T, Natori Y (2017) Evaluation of Seizures in Patients with Chronic Subdural Hematoma Treated by Burr-Hole Surgery and Risk Factors for Seizures. Int J Brain Disord Treat 3:018. doi. org/10.23937/2469-5866/1410018

Received: February 16, 2017: Accepted: March 24, 2017: Published: March 27, 2017

Copyright: (C) 2017 Yamada T, et al. This is an open-access article distributed under the terms of the Creative Commons Attribution License, which permits unrestricted use, distribution, and reproduction in any medium, provided the original author and source are credited. 


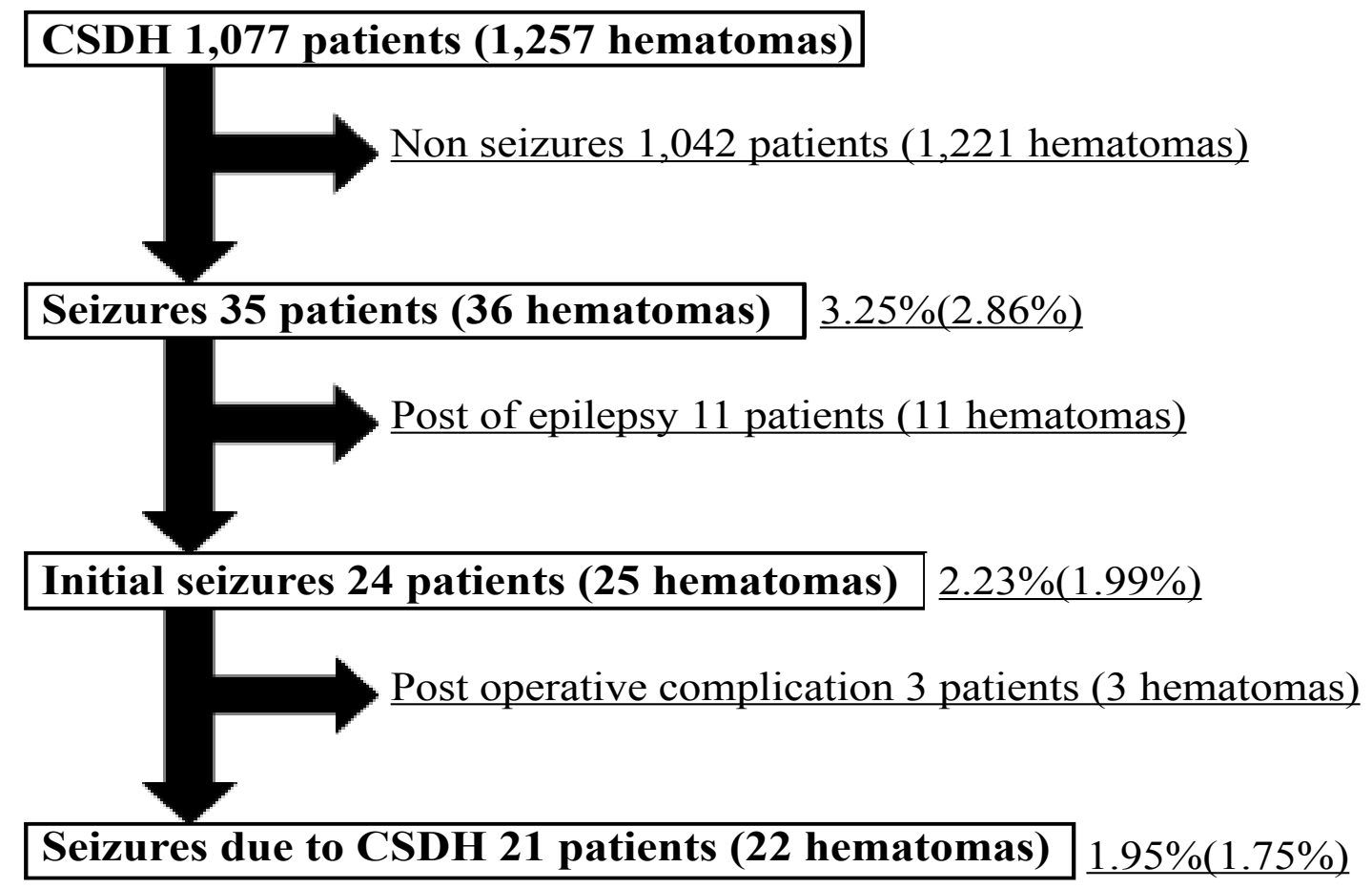

Figure 1: Patients with chronic subdural hematoma who had seizures as a complication.

1,077 patients $(1,257$ hematomas) underwent burr-hole surgery.

1,042 patients $(1,221$ hematomas) had no seizures.

35 patients (36 hematomas) had seizures.

11 patients (11 hematomas) had a history of epilepsy.

24 patients (25 hematomas) had initial seizures.

3 patients ( 3 hematomas) had seizures as postoperative complications.

Seizures were caused by CSDH in 21 patients ( 22 hematomas).

tion in 35 patients ( 36 hematomas), 11 of whom ( 11 hematomas) had a history of epilepsy. The type of epilepsy was posttraumatic symptomatic epilepsy in 6 patients ( 6 hematomas), symptomatic epilepsy after cerebral infarction in 3 patients ( 3 hematomas), symptomatic epilepsy after cerebral hemorrhage in 1 patient (1 hematoma), and idiopathic epilepsy in 1 patient ( 1 hematoma). When the 11 patients who had a past history of epilepsy were excluded, there were 24 patients with seizures as a complication $(24$ of 1,077 patients, $2.23 \%$; 25 of 1,221 hematomas, $1.99 \%$ ). Furthermore, patients who had seizures associated with any of the following postoperative concurrent diseases were excluded: acute subdural hematoma, cerebral infarction, or subdural abscess. We judged that seizures were caused by CSDH in 21 (1.95\%) of the 1,077 patients (22 of 1,221 hematomas, $1.75 \%$ ) (Figure 1). We diagnosed seizures on the basis of clinical findings, and electroencephalography was not necessarily performed. We diagnosed as a seizures with sightings of convulsions. The convulsions were general or partial seizures in some cases.

The following variables were studied: age, sex, activities of daily living (ADL) before onset, hematoma side, operation side, symptoms on admission, neurologic findings (level of consciousness, degree of hemiplegia) on admission, preoperative hematoma volume, preoperative hematoma density, initial episode or recurrence, whether the hematoma was organized or not, the presence or absence of trauma, seizure type (general or partial), time of seizure onset (preoperative or postoperative), treatment of seizures, control of seizures, ADL and outcome at discharge, and recurrence of CSDH. Furthermore, we compared patients who had seizures with those who did not have seizures. The following variables were studied: age, sex, smoking, drinking, hypertension, diabetes disease, liver disorder, renal function, malignant tumor, ischemic heart disease, stroke, neurosurgery, use of anticoagulant agents or not, use of antiplatelet agents or not, presence or absence of trauma, initial episode or recurrence, neurologic findings (level of consciousness, degree of hemiplegia) on admission, hematoma side, operation side, whether the hematoma was organized or not, irrigation solution, experience of the operator, preoperative hematoma density, preoperative hematoma volume, and discharge outcome. The results were analyzed statistically with the use of $\mathrm{t}$-tests or chi-square tests. $\mathrm{P}$ values less than 0.05 were considered to indicate statistical significance. We retrospectively ascertained the study variables from the patients' medical records. If a medical record did not include the required variables or CT was not performed, we excluded it from analysis. ADL was evaluated according to the modified rankin scale (mRS), and the level of consciousness was evaluated according to the glasgow coma 

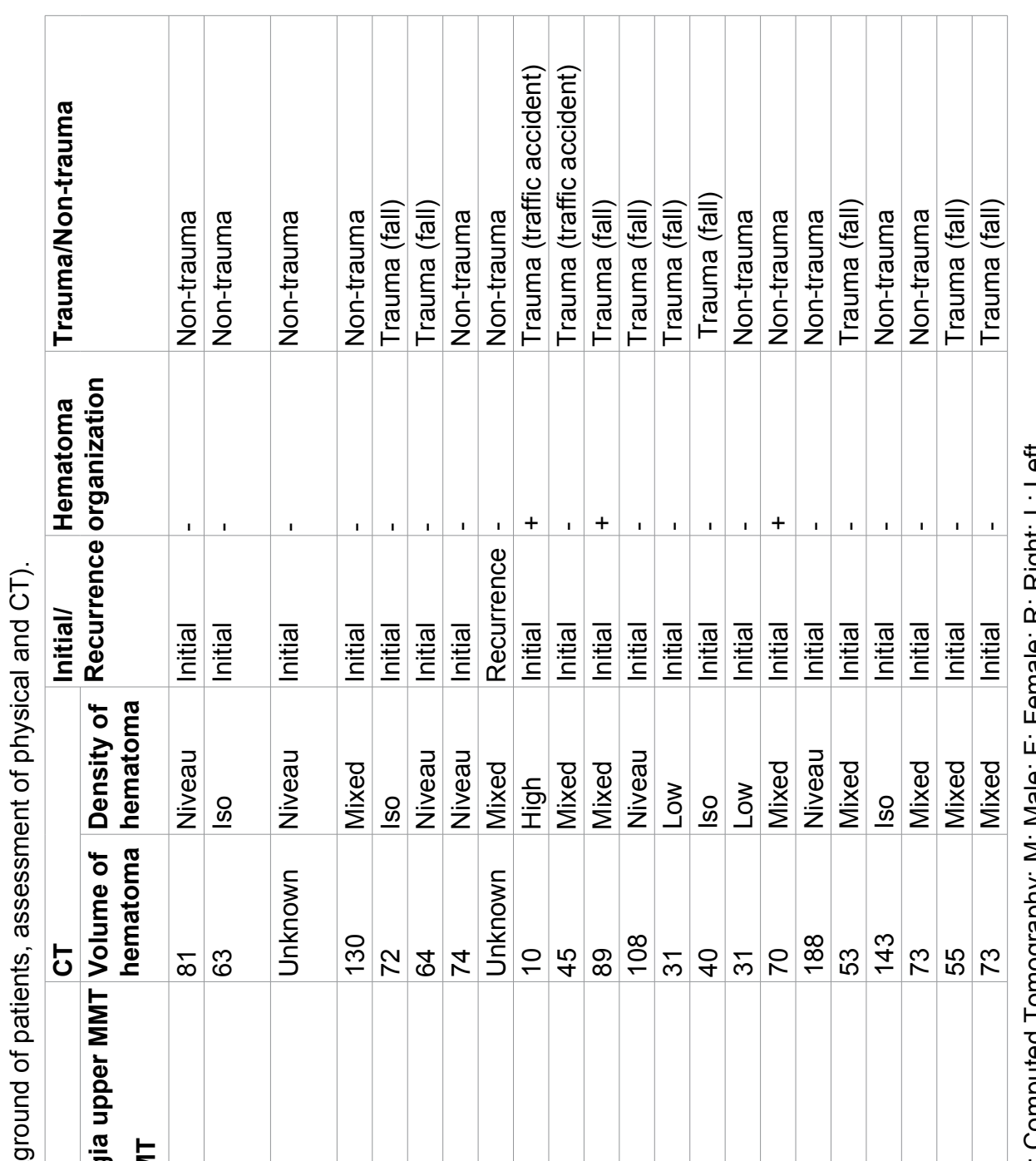

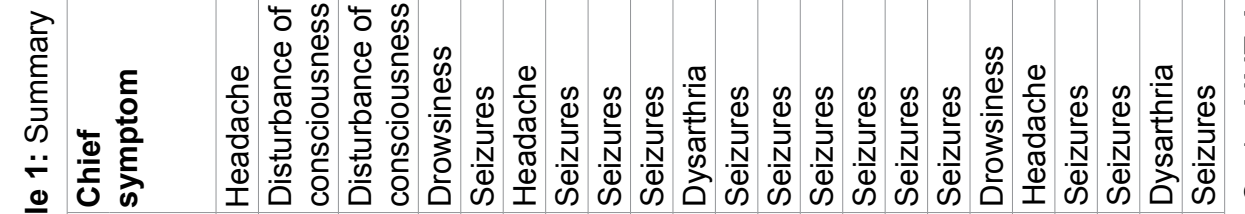

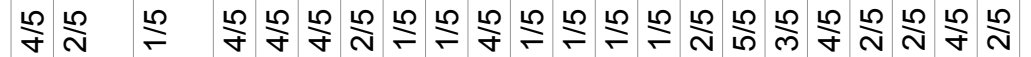

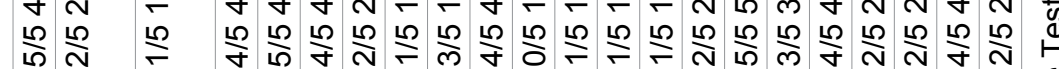

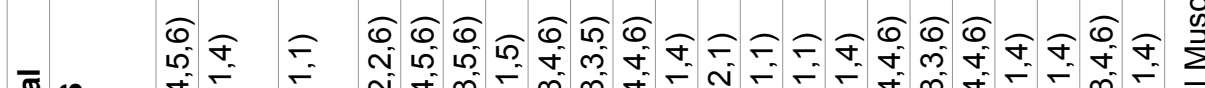

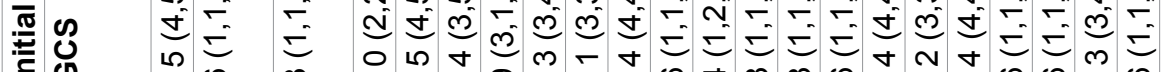
L 


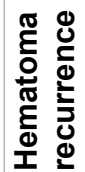

ก

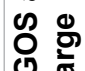

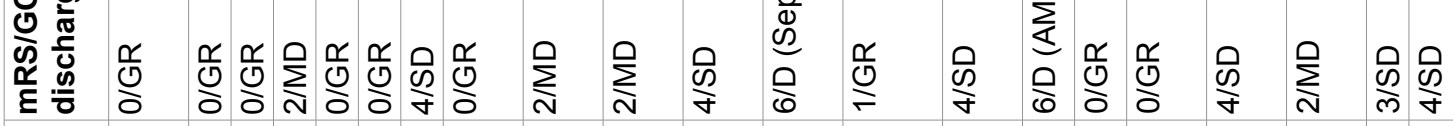

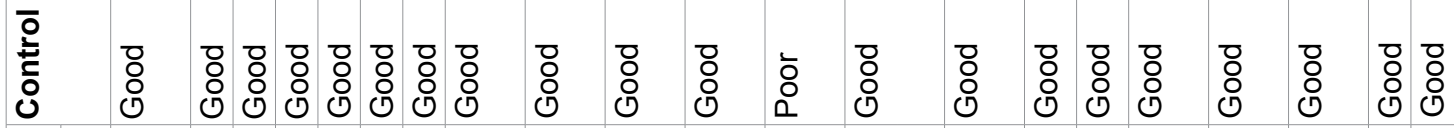

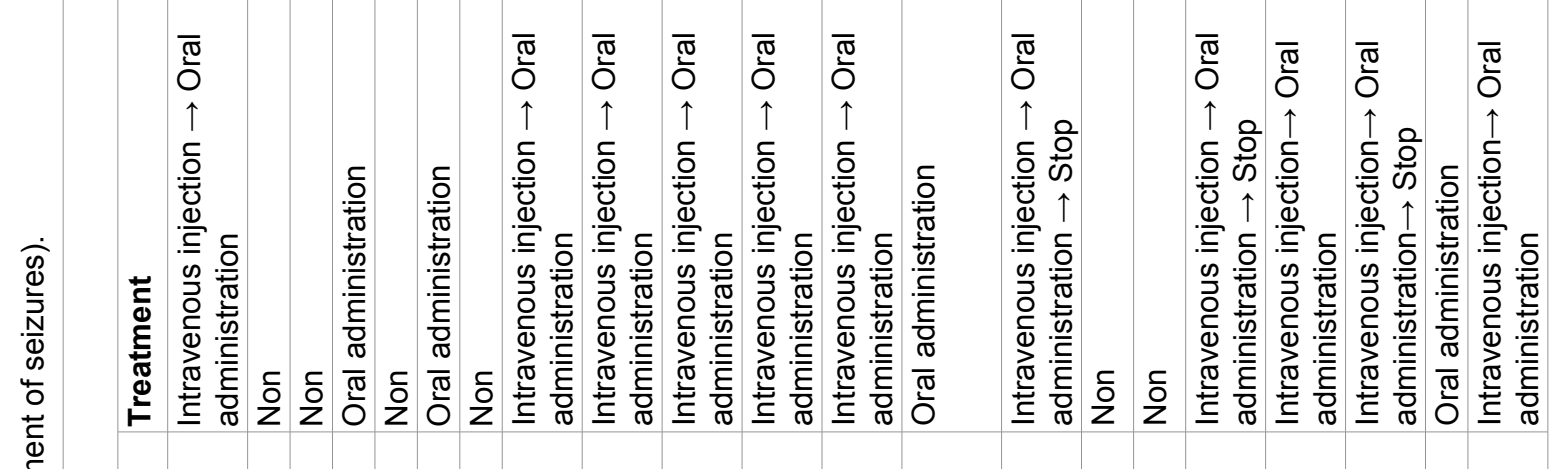

हैำ

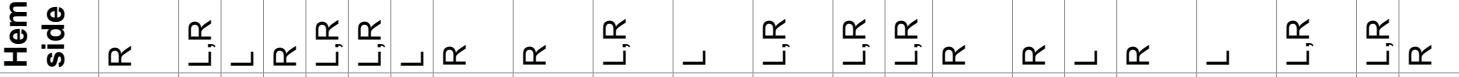

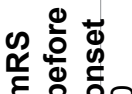

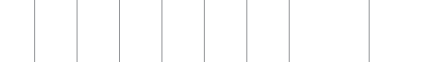

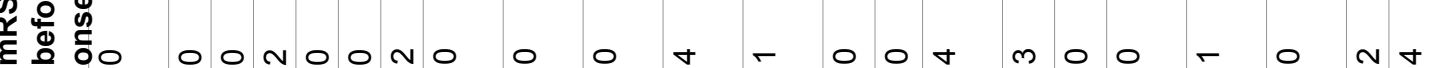

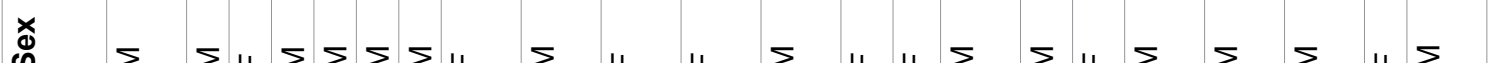

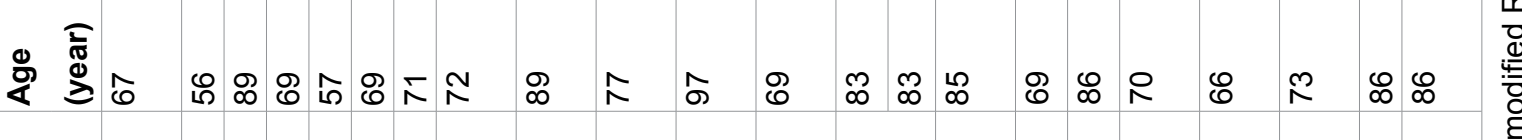
J 
scale (GCS). Hemiplegia was evaluated on manual muscle testing (MMT).

The hematoma volume was estimated by region-of-interest (ROI) analysis of CT images. The hematoma areas on each CT image were totaled to derive the hematoma volume. We classified the hematoma density as low, isodense (iso), or high relative to the brain gray matter. When high density was mixed with low density, the hematoma density was assumed to be mixed. When low density and high density were mirror images, the hematoma density was assumed to be niveau. Diagnosis of hematoma organization was performed by intraoperative finding. When we confirmed organized hematoma rather than liquid during surgery, we diagnosed it as hematoma organization. The outcome at discharge was evaluated according to the glasgow outcome scale (GOS). Recurrence of a CSDH was defined as reoperation within 3 months after initial surgery.

\section{Results}

The clinical characteristics of the 21 patients ( 22 hematomas) who had seizures are summarized in (Table 1 and Table 2). The mean age ( \pm SD) of the patients with seizures was 75.5 ( \pm 11.0 ) years, and the male: female ratio was 2:1. As for ADL before onset, 17 patients could independently look after their own affairs (mRS score, 2 or less). The hematoma site was the right side in 8 patients, the left side in 5 patients, and both sides in 8 patients. The operation side was the right side in 11 patients, the left side in 9 patients, and both sides in 1 patient. The main symptoms on admission were seizures in 12 patients, headache in 3 patients, disturbed consciousness in 2 patients, drowsiness in 2 patients, and dysarthria in 2 patients. As for the degree of hemiplegia on admission, the MMT score was 2 or less in 12 patients, 3 or 4 in 8 patients, and 5 in 1 patient. The mean hematoma volume $( \pm \mathrm{SD})$ was $74.6( \pm 41.8) \mathrm{ml}$. The hematoma density was mixed in 9 hematomas, niveau in 6 hematomas, iso in 4 hematomas, low in 2 hematomas, and high in 1 hematoma. Twenty-one hematomas underwent initial burr-hole surgery; 1 hematoma recurred. There were 3 organized hematomas, and 19 normal hematomas in the patients with CSDH. Ten patients clearly had a history of trauma. The seizure type was general attacks in 9 patients, partial attacks in 3 patients, and partial attacks followed by general attacks in 9 patients. The onset of seizures was preoperative in 11 patients, only intraoperative in 1 patient, only postoperative in 1 patient, and preoperative and postoperative in 8 patients. As for the treatment of seizures, 11 patients received intravenous and oral anticonvulsants, 4 patients received only oral anticonvulsants, and 6 patients were not treated. Seizures were well controlled by oral anticonvulsants in 11 patients. Furthermore, in 9 patients seizures were well controlled without treatment. Status epilepticus developed in 1 patient in whom seizures were poorly controlled, and the patient died of sepsis. As for the ADL at discharge, 13 patients could independently look after their own affairs (mRS score, 2 or less). In 9 patients, ADL at discharge had decreased as compared with the status at admission. Two patients died, one of acute myocardial infarction and the other of sepsis. There was no recurrence in the patients who had seizures. The characteristics of the patients with seizures are compared with those of the patients without seizures in (Table 3 and Table 4). There were statistically significant differences in the level of consciousness (GCS) on admission, the degree of hemiplegia on admission, the organization status of hematoma, and discharge outcome.

\section{Discussion}

The 35 patients with CSDH (36 hematomas) were classified into 3 types according to the cause of seizures. Type 1 included patients who had seizures caused directly by CSDH. Type 2 included patients who had a past history of epilepsy. Type 3 included patients with seizures that developed as a complication of burr-hole surgery. Type 1 comprised 21 patients (1.95\%) with 22 hematomas (1.75\%). Type 2 comprised 11 patients (1.02\%) with 11 hematomas (0.88\%). Type 3 comprised 3 patients $(0.28 \%)$ with 3 hematomas $(0.24 \%)$. The frequency of seizures tended to be lower than that reported previously (2.3\% to $20.4 \%$ ) [29]. The present study focused on type 1 seizures, i.e., seizures caused directly by CSDH. We observed the patients from the date of diagnosis of $\mathrm{CSDH}$ or symptom onset to 1 month after surgery. Differences in the frequency of seizures among studies are thought to depend on whether all 3 types of seizures are included and when the observation period is terminated.

The onset of seizures was preoperative in 19 patients and postoperative in only 1 patient. In many patients, the seizures were well controlled after hematoma removal. The presence of hematoma is thought to contribute to the development of seizures. Reduced blood flow in the local cerebral cortex or gliosis caused by hematoma capsule formation is thought to participate in the mechanism of seizures $[4,6]$. The fact that many patients with seizures had organized hematoma also suggests that hematoma influences seizures. One study reported that a prolonged period is necessary for a hematoma to become organized [10]. Long-term exposure to pressure due to a hematoma may reduce local blood flow in the cerebral cortex. In addition, microcirculatory disturbances have also been reported to participate in the organization of hematoma. Reduced blood flow caused by circulatory disease may also contribute to seizures. Seizures developed intraoperatively in 1 patient, and the use of an intraoperative drainage tube is considered a potential risk factor. As for the type of seizures, 3 patients had partial attacks, 9 patients had partial attacks followed by general attacks, and 9 patients had general attacks. The onset of many general attacks is not witnessed by a bystander, and the possibility that partial attacks led to general attacks should be considered. Because many patients initially had partial attacks, seizures were most likely induced by the presence of hematoma.

The factors that differed significantly between patients with seizures and those without seizures were the level of 
Table 3: Background of the seizure and non-seizure groups.

\begin{tabular}{|c|c|c|c|c|c|c|}
\hline \multicolumn{2}{|l|}{ Background } & \multirow{2}{*}{$\begin{array}{l}\text { Seizures } \\
\text { Patients = } 21 \\
\text { Hematomas = } 22\end{array}$} & \multirow{2}{*}{$\begin{array}{l}\text { Non-seizures } \\
\text { Patients = 1,056 } \\
\text { Hematomas = 1,235 }\end{array}$} & $\begin{array}{l}\text { Odds } \\
\text { ratio }\end{array}$ & $95 \% \mathrm{Cl}$ & \multirow[t]{2}{*}{ P value } \\
\hline & & & & & & \\
\hline Age & Mean $\pm S D$ years & $75.5 \pm 11.0$ & $76.2 \pm 11.3$ & - & - & 0.787 (t-test) \\
\hline \multirow[t]{2}{*}{ Sex } & Male & 14 & 644 & \multirow[t]{2}{*}{1.28} & \multirow[t]{2}{*}{$0.512-3.197$} & \multirow[t]{2}{*}{0.597 ( $x^{2}$-test $)$} \\
\hline & Female & 7 & 412 & & & \\
\hline \multirow[t]{3}{*}{ Smoking } & + & 7 & 259 & \multirow[t]{2}{*}{1.535} & \multirow[t]{2}{*}{ 0.613-3.844 } & \multirow[t]{2}{*}{$0.357\left(x^{2}\right.$-test $)$} \\
\hline & - & 14 & 795 & & & \\
\hline & Unknown & 0 & 2 & - & - & - \\
\hline \multirow{4}{*}{$\begin{array}{l}\text { Alcohol } \\
\text { consumption }\end{array}$} & $\geqq 1$ go & 4 & 147 & \multirow[t]{3}{*}{-} & \multirow[t]{3}{*}{-} & \multirow[t]{3}{*}{0.784 ( $X^{2}$-test $)$} \\
\hline & About 1 go & 3 & 143 & & & \\
\hline & $<1$ go & 14 & 764 & & & \\
\hline & Unknown & 0 & 2 & - & - & - \\
\hline \multirow[t]{2}{*}{ Hypertension } & + & 13 & 536 & \multirow[t]{2}{*}{1.576} & \multirow[t]{2}{*}{$0.648-3.835$} & \multirow[t]{2}{*}{$0.312\left(x^{2}\right.$-test $)$} \\
\hline & - & 8 & 520 & & & \\
\hline \multirow[t]{2}{*}{ Diabetes mellitus } & + & 4 & 169 & \multirow[t]{2}{*}{1.235} & \multirow[t]{2}{*}{$0.410-3.716$} & \multirow[t]{2}{*}{0.707 ( $x^{2}$-test $)$} \\
\hline & - & 17 & 887 & & & \\
\hline \multirow[t]{2}{*}{ Liver disorder } & + & 2 & 145 & \multirow[t]{2}{*}{0.661} & $0.152-2.869$ & $0.578\left(X^{2}\right.$-test $)$ \\
\hline & - & 19 & 911 & & & \\
\hline eGFR & $<60$ & 6 & 349 & 0.81 & $0.312-2.107$ & $0.666\left(x^{2}\right.$-test $)$ \\
\hline & $\geqq 60$ & 15 & 707 & & & \\
\hline Malignant tumor & + & 4 & 165 & 1.271 & $0.422-3.824$ & 0.669 ( $x^{2}$-test $)$ \\
\hline & - & 17 & 891 & & & \\
\hline Ischemic heart & + & 6 & 219 & 1.529 & $0.586-3.986$ & $0.382\left(x^{2}\right.$-test $)$ \\
\hline disease & - & 15 & 837 & & & \\
\hline Stroke & + & 4 & 181 & 1.137 & $0.378-3.420$ & $0.818\left(X^{2}\right.$-test $)$ \\
\hline & - & 17 & 875 & & & \\
\hline Neurosurgery & + & 4 & 187 & 1.093 & $0.364-3.287$ & $0.874\left(X^{2}\right.$-test $)$ \\
\hline & - & 17 & 869 & & & \\
\hline Anticoagulant & + & 2 & 92 & 1.103 & $0.253-4.810$ & $0.896\left(X^{2}\right.$-test $)$ \\
\hline agents & - & 19 & 964 & & & \\
\hline Antiplatelet agents & + & 6 & 182 & 1.921 & $0.735-5.017$ & 0.175 (X'test) \\
\hline & - & 15 & 874 & & & \\
\hline Trauma & + & 10 & 623 & 0.631 & $0.266-1.501$ & 0.294 ( $X^{2}$-test $)$ \\
\hline & - & 11 & 433 & & & \\
\hline Initial or & Initial & 20 & 1114 & 2.172 & $0.289-16.329$ & $0.294\left(X^{2}-\right.$ test $)$ \\
\hline recul & Recurrence & 1 & 121 & & & \\
\hline
\end{tabular}

${ }^{* *} p<0.01$; SD: Standard Deviation; eGFR: estimated Glomerular Filtration Rate.

consciousness (GCS) on admission, degree of hemiplegia on admission, and the organization status of hematoma. These factors are considered risk factors for convulsions. There was no significant difference in age, personal habits (smoking status, alcohol intake), or past medical history between patients with seizures and those without seizures. There was also no significant difference in past trauma or neurosurgical procedures that than can potentially damage the cerebral cortex. Therefore, seizures were apparently not caused by damage of the cerebral cortex, and the presence of CSDH is thought to have contributed to the onset of seizures. Because the volume and density of hematoma did not differ significantly between patients with seizures and those without seizures, the cause of seizures is apparently not only simple pressure applied by the hematoma. The possibility that capsule formation around the CSDH might have stimulated the cerebral cortex should be considered. Symptomatic epilepsy caused by trauma or stroke might have been affected by the formation of CSDH.

Seizures were the main symptom on admission in 12 patients. Although seizures associated with symptoms such as disturbed consciousness and dullness were not directly witnessed, if we assume that these symptoms are caused by seizures, many patients probably had seizures before presentation. Therefore, disturbed consciousness is thought to 
Table 4: Clinical findings and computed tomographic findings and of the seizure and non-seizure groups.

\begin{tabular}{|c|c|c|c|c|c|c|}
\hline Factor & & \multirow{2}{*}{$\begin{array}{l}\text { Seizures } \\
\text { Patients = } \mathbf{2 1} \\
\text { Hematomas = } 22 \\
6\end{array}$} & \multirow{2}{*}{$\begin{array}{l}\text { Non-seizures } \\
\text { Patients = 1,056 } \\
\text { Hematomas = 1,235 } \\
871\end{array}$} & \multirow[t]{2}{*}{$\begin{array}{l}\text { Odds } \\
\text { ratio } \\
-\end{array}$} & \multirow{2}{*}{$\begin{array}{l}95 \% \mathrm{Cl} \\
-\end{array}$} & \multirow{2}{*}{$\begin{array}{l}\text { P value } \\
{ }^{* *} 4.92 \times 10^{-21}\left(x^{2} \text {-test }\right)\end{array}$} \\
\hline \multirow[t]{3}{*}{ GCS } & $14-15$ & & & & & \\
\hline & $9-13$ & 6 & 152 & & & \\
\hline & $3-8$ & 9 & 33 & & & \\
\hline \multirow[t]{4}{*}{ Upper MMT } & 5 & 3 & 535 & \multirow[t]{3}{*}{-} & \multirow[t]{3}{*}{-} & \multirow[t]{3}{*}{ **1.34 × $10^{-13}\left(\mathrm{X}^{2}\right.$-test $)$} \\
\hline & 3,4 & 7 & 600 & & & \\
\hline & $0,1,2$ & 12 & 98 & & & \\
\hline & loss & 0 & 2 & - & - & - \\
\hline \multirow[t]{4}{*}{ Lower MMT } & 5 & 1 & 488 & \multirow[t]{3}{*}{-} & \multirow[t]{3}{*}{-} & \multirow[t]{3}{*}{${ }^{* *} 5.16 \times 10^{-17}\left(x^{2}\right.$-test $)$} \\
\hline & 3,4 & 8 & 650 & & & \\
\hline & $0,1,2$ & 13 & 94 & & & \\
\hline & Loss & 0 & 3 & - & - & - \\
\hline \multirow[t]{3}{*}{ Hematoma side } & Right & 8 & 287 & \multirow[t]{3}{*}{-} & \multirow[t]{3}{*}{-} & \multirow[t]{3}{*}{$0.383\left(X^{2}\right.$-test $)$} \\
\hline & Left & 5 & 392 & & & \\
\hline & Bilateral & 8 & 377 & & & \\
\hline \multirow[t]{3}{*}{ Operation side } & Right & 11 & 374 & \multirow[t]{3}{*}{-} & \multirow[t]{3}{*}{-} & \multirow[t]{3}{*}{$0.164\left(X^{2}\right.$-test $)$} \\
\hline & Left & 9 & 501 & & & \\
\hline & Bilateral & 1 & 181 & & & \\
\hline \multirow[t]{2}{*}{ Organization } & + & 3 & 7 & \multirow[t]{2}{*}{29.23} & \multirow[t]{2}{*}{ 6.99-122.21 } & \multirow[t]{2}{*}{${ }^{* *} 2.31 \times 10^{-12}\left(X^{2}\right.$-test $)$} \\
\hline & - & 18 & 1228 & & & \\
\hline Irrigation solution & Lactated ringer & 5 & 224 & - & - & 0.338 ( $\mathrm{x}^{2}$-test $)$ \\
\hline & Saline & 4 & 408 & & & \\
\hline & Artificial CSF & 13 & 603 & & & \\
\hline Experience of & Resident & 3 & 257 & - & - & 0.640 ( $x^{2}$-test $)$ \\
\hline & Senior resident & 8 & 462 & & & \\
\hline & Neurosurgeon & 11 & 516 & & & \\
\hline CT density & Low density & 2 & 150 & - & - & 0.124 ( $x^{2}$-test $)$ \\
\hline & Isodensity & 4 & 451 & & & \\
\hline & High density & 1 & 137 & & & \\
\hline & Mixed density & 9 & 298 & & & \\
\hline & Niveau & 6 & 196 & & & \\
\hline & Unknown & 0 & 3 & - & - & - \\
\hline Preoperative & Mean \pm SD ml & $74.6 \pm 41.8$ & $89.3 \pm 40.8$ & - & - & 0.177 (t-test) \\
\hline & Unknown & 2 & 87 & - & - & \\
\hline Discharge GOS & GR, MD & 13 & 979 & - & - & ${ }^{* *} 5.15 \times 10^{-7}\left(x^{2}\right.$-test $)$ \\
\hline & SD, VS & 6 & 65 & & & \\
\hline & $\mathrm{D}$ & 2 & 12 & & & \\
\hline
\end{tabular}

${ }^{* *} \mathrm{p}<0.01$; SD: Standard Deviation; GCS: Glasgow Coma Scale; MMT: Manual Muscle Test; CT: computed tomography; GOS: Glasgow Outcome Scale.

be considerable after seizures. Todd's paralysis is considered to frequently develop after seizures. Thus, risk factors for seizures might not be associated with neurologic findings on admission. Disturbed consciousness and hemiplegia on admission are considered to be caused by seizures. Organization of a hematoma is thought to contribute to the risk of seizures. Even as CSDH undergoes organization, the main symptoms include seizures [10]. Organizing CSDH is difficult to diagnose on preoperative imaging alone and is usually diagnosed at operation [10]. Therefore, it is difficult to predict seizures before operation. 
The results of our study suggest that the organization of hematoma is a risk factor for seizures. However, it is considered difficult to predict the risk of seizures before onset. When we examine patients with $\mathrm{CSDH}$ who have disturbed consciousness or severe hemiplegia, the possibility that the patient has had seizures should be borne in mind. Seizures are relatively rare. Even if seizures develop, they can be well controlled by hematoma removal or by treatment with oral anticonvulsant agents as required. Therefore, prophylactic treatment with anticonvulsants is not necessary in all cases. It is necessary to treat with anticonvulsants to the case where the seizures actually occurred and the case where the organizing was confirmed during the operation. The patients with seizures had poor outcome at the time of the discharge, and enough control of seizures is necessary.

\section{Conclusions}

We studied patients who underwent burr-hole surgery for $\mathrm{CSDH}$ associated with seizures. Seizures are relatively rare in patients with CSDH. In patients with CSDH who have seizures, the presence of hematoma causes seizures, and many patients consult a physician mainly because of seizures. It is difficult to predict the risk of seizures before onset. Seizures can be relatively well controlled by hematoma removal, and prophylactic treatment with anticonvulsant drugs is unnecessary. When we examine patients with CSDH who have disturbed consciousness or strong paralyses, the possibility of seizures should be considered.

\section{Ethical Approval}

This study got the approval of the Ethical Review Board of our hospital. For this type of study formal consent is not required.

\section{References}

1. Yamada T, Natori Y (2013) Risk factors associated with recurrence after burr-hole evacuation for chronic subdural hematoma. Jpn J Neurosurg 22: 125-132.

2. Chen CW, Kuo JR, Lin HJ, Yeh CH, Wong BS, et al. (2004) Early post-operative seizures after burr-hole drainage for chronic subdural hematoma: correlation with brain CT findings. J Clin Neurosci 11: 706-709.

3. Grobelny BT, Ducruet AF, Zacharia BE, Hickman ZL, Andersen KN, et al. (2009) Preoperative antiepileptic drug administration and the incidence of postoperative seizzures following bur hole-treated chronic subdural hematoma. J Neurosurg 111: 1257-1262.

4. Huang YH, Yang TM, Lin YJ, Tsai NW, Lin WC, et al. (2011) Risk Factor and Outcome of Seizures After Chronic Subdural Hematoma. Neurocrit Care 14: 253-259.

5. Kotwica Z, Brzezinski J (1991) Epilepsy in chronic subdural hematoma. Acta Neurochir (Wien) 113: 118-120.

6. Neshige S, Sekihara Y, Ishii N, Sato M, Ota S, et al. (2014) Clinical and radiological studies of seizure in chronic subdural hematoma -case control study. Clin Neurol 54: 869875.

7. Ohno K, Maehara T, Ichimura K, Suzuki R, Hirakawa K, et al. (1993) Low incidence of seizures in patients with chronic subdural hematoma. J Neurol Neurosurg Psychiatry 56: 1231-1233.

8. Rubin G, Rappaport ZH (1993) Epilepsy in chronic subdural hematoma. Acta Neurochir (Wien) 123: 39-42.

9. Sabo RA, Hanigan WC, Aldag JC (1995) Chronic Subdural Hematomas and Seizures: The Role of Prophylactic anticonvulsive medication. Surg Neurol 43: 579-582.

10. Yamada T, Natori Y (2012) Examination of five cases of organized chronic subdural hematoma. Neurosurg Emerg 17: 81-86. 